\title{
LEITURA LENTA DA OBRA DE ARTE COMO PROPOSTA PARA EDUCAÇÃO ESTÉTICA: CONTRIBUIÇÕES DE MARX E VIGOTSKI
}

Priscila de Souza Chisté ${ }^{1}$

\section{Resumo}

$\mathrm{O}$ artigo sinaliza, por meio de pesquisa bibliográfica, uma proposta de Educação Estética em diálogo com estudos de Marx e Vigotski. Através das teorias marxianas, apresenta reflexões sobre Estética no contexto contemporâneo e, com Vigotski, busca compreender pressupostos da Educação Estética. Sugere um caminho, a partir das Artes Visuais, para se educar esteticamente diante do conceito de leitura lenta da obra de arte. Considera que uma das possibilidades para alcançar tal intento é proporcionar intensos, diversificados e contínuos encontros com obras de arte, mediar leituras de imagens que evidenciem tanto os aspectos poéticos e intertextuais quanto os formais dessas obras, ampliados pelo conhecimento do universo do artista e dos modos de legitimação e divulgação das obras e, por fim, propor assuntos relacionados com os interesses dos educandos.

Palavras-chave: Educação Estética; Arte; Vigotski; Marx

\section{INTRODUÇÃO}

A Educação Estética constitui-se como desafio frente à sociedade capitalista. Marx nos

\footnotetext{
${ }^{1}$ Priscila de Souza Chisté, licenciada em Educação Artística e Pedagogia, possui mestrado e doutorado em Educação pela Universidade Federal do Espírito Santo. Atua como professora do Instituto Federal do Espírito Santo na Educação Profissional de Jovens e Adultos (Proeja), Licenciatura em Letras e nos Programas de PósGraduação em Ensino de Ciências e Matemática (Educimat), Letras (Profletras) e Humanidades. Endereço: Avenida Vitória n. 1729, Jucutuquara, Vitória - Espírito Santo. E-mail: pchiste@ifes.edu.br.
} 
ajuda a pensar sobre essa questão quando pontua que a crescente instrumentalização da humanidade afasta, cada vez mais, os indivíduos das vivências sensíveis. Com o intuito de contrapor esse fato, o artigo em tela sinaliza um possível caminho para a Educação Estética, por meio das Artes Visuais, a partir de pesquisa bibliográfica referente aos estudos de Marx, como apontado, e também de Vigotski.

Na primeira seção, apresenta contribuições dos estudos marxianos para reflexões sobre Estética no contexto contemporâneo. Já na segunda, aponta a contribuição de Vigotski para os estudos sobre a Educação Estética, sob a luz das ideias marxianas. A seguir, na terceira seção, sugere uma proposta de Educação Estética por meio das Artes Visuais, em especial, a partir do conceito de leitura lenta de Vigotski. Considera que uma das possibilidades de se educar esteticamente é proporcionar intensos, diversificados e contínuos encontros com obras de arte, mediar leituras de imagens que evidenciem tanto os aspectos poéticos e intertextuais quanto os formais dessas obras, ampliados pelo conhecimento do universo do artista e dos modos de legitimação e divulgação das obras e, por fim, propor assuntos relacionados com os interesses dos educandos.

\section{CONTRIBUIÇÕES DOS ESTUDOS MARXIANOS PARA AS REFLEXÕES SOBRE A ESTÉTICA NO CONTEXTO CONTEMPORÂNEO}

No dia a dia, em diferentes contextos, é muito comum ouvir falar sobre estética, principalmente relacionada com a beleza física. Para a filosofia, estética relaciona-se com o estudo do belo e do sentimento que esse suscita nos homens. A estética aparece ligada à noção de beleza e, por isso, a arte tem lugar privilegiado nessa reflexão, pois, durante muito tempo, ela teve como função exprimir a beleza de modo sensível.

Etimologicamente, a palavra estética origina-se do grego, aisthesis, com o significado de faculdade do sentir, compreensão pelos sentidos, percepção totalizante, reafirmando a ligação da estética com a arte. Assim, o objeto artístico é aquele que se oferece ao sentimento e à percepção. Segundo Santaella (1994), a raiz aisth, do verbo aisthanomai, quer dizer sentir com os sentidos, ou seja, com a rede de percepções físicas. Para o Dicionário Básico de Filosofia de Japiassú e Marcondes (2008), estética é um dos ramos tradicionais da filosofia. O termo foi criado por Alexander Von Baumgarten, no século XVIII, para designar o estudo da sensação, a ciência do belo, e referia-se à empiria do gosto subjetivo, àquilo que agrada aos 
sentidos, com fins à elaboração de uma ontologia do belo.

Terry Eagleton (1993) destaca que a estética nasceu como um discurso sobre o corpo. "Em sua formulação original, pelo filósofo alemão Alexander Baumgarten, o termo não se refere primeiramente à arte, mas com o grego aisthesis, a toda a região de percepção e sensação humanas, em contraste com o domínio mais rarefeito do pensamento conceitual" (EAGLETON, 1993, p. 17).

No ano de 1735, Baumgarten publicou Reflexões filosóficas sobre algumas questões pertinentes à poesia e, nesse artigo, pela primeira vez, empregou a palavra "estética", definindo-a como a ciência da percepção geral. Ele acreditava que o campo da lógica deveria ser ampliado por uma estética que incluiria a coisa cognoscível sensitivamente. Em sua obra posterior, Aisthetica (1750), essa ciência da percepção foi tomada como sinônimo de conhecimento pelos sentidos e partia da ideia de que existe uma estética natural, como uma capacidade inata que o ser humano possui para o pensamento belo, e também uma estética adquirida, que pode acontecer por meio do ensino ou da prática.

Nesse sentido, a estética surge do reconhecimento de que o mundo da percepção e da experiência não pode ser simplesmente derivado de leis universais abstratas, mas requer do seu discurso mais inferior uma lógica interna. $\mathrm{O}$ surgimento da estética relaciona-se também com a busca pela ascensão da burguesia em frente à aristocracia feudal, por uma ordem universal de sujeitos livres, iguais e autônomos. Por isso, era preciso pensar em um tipo inteiramente novo de sujeito, um sujeito que, assim como a obra de arte, "[...] descobre a lei na profundeza de sua própria identidade livre, e não em algum poder externo opressivo" (EAGLETON, 1993, p. 21).

Nesse contexto, coloca-se um novo desafio ideológico à ordem dominante. Isso produz novas dimensões do sentimento para além dos limites propostos pelo Absolutismo. Para que o poder fosse legitimado e conquistado pela burguesia, ocorreu um processo profundo de emancipação política em que a liberdade e a compaixão, a imaginação e o corpo foram ouvidos no interior do discurso de um racionalismo repressivo.

Baumgarten concebia a estética como equivalente sensual da lógica, pois estava para a sensorialidade, conhecimento tido como inferior, do mesmo modo que a lógica estava para o pensamento, conhecimento superior. É a partir de Baumgarten que essa área se tornou uma disciplina autônoma e culminou na Educação Estética, que teve início com os estudos de Schiller. 
Friedrich Schiller, assim como Imanuel Kant, ${ }^{2}$ insere-se no contexto Iluminista, marcado pela conscientização histórica, resultado do esforço de um pequeno grupo de literatos, escritores, críticos e filósofos. Vários episódios que ocorreram durante a Revolução Francesa, entre eles a execução do rei Luis XVI, deixaram Schiller decepcionado e o levaram a concluir que o Iluminismo não bastava para aperfeiçoar as relações políticas. Caberia somente à arte, inserida em um século indigno e bárbaro, o papel de purificar a humanidade.

Para Schiller a arte é o impulso mais eficaz do ser humano, o meio mais efetivo de autorrealização humana e, por conseguinte, a Educação Estética deveria fomentar uma revolução total da maneira de sentir, tornando-se a base da construção de uma verdadeira liberdade humana.

Schiller (2002) tentou superar o seu mestre, Kant, no tratado A Educação Estética do homem numa série de cartas. Nas cartas, ele diagnostica as questões centrais de sua época: a alienação, o isolamento, a divisão do trabalho, a consequente fragmentação do indivíduo, o Estado moderno e o desenvolvimento científico e cultural. Para ele, somente a formação da sensibilidade seria capaz de tirar os homens da condição da barbárie. Nesse sentido, considera o artista como o indivíduo capaz de se resguardar de "corrupções de sua época".

A ideia de Schiller era criar cidadãos que colaborassem com a liberdade política e civil. Para ele, a Educação Estética era a tarefa suprema do homem e, embora factível, não poderia ser inteiramente realizada, pois a humanidade jamais seria plenamente emancipada. Porém, acreditava que o indivíduo que se cultivasse e se enobrecesse moralmente não renunciaria à esperança de um dia vir a ser livre. Nesse sentido, educar e ser educado esteticamente significaria educar e ser educado pela soberania da imaginação.

Contudo, no final do século XIX, a partir das ideias schillerianas, Marx, ao criticar o capitalismo industrial, as capacidades atrofiadas, os poderes dissociados e a totalidade da

\footnotetext{
${ }^{2}$ Para Kant (1995a, 1995b, 1995c), o homem, em sua busca pelo conhecimento de mundo, precisa procurar também a harmonia com o mundo, pois, para haver conhecimento, é preciso que as nossas faculdades se ajustem à realidade material. É a contemplação desta forma pura de cognição, a harmonia com o mundo, que vem a ser estética. O filósofo acredita que existem duas fontes do conhecimento humano: a sensibilidade e o entendimento. Por meio da primeira, os objetos nos são dados; pela segunda, são pensados. Só pela conjugação desses dois elementos é possível a experiência do real. Portanto, para Kant, não somos capazes de conhecer as coisas como elas são em si, só conhecemos realmente o mundo dos fenômenos, da experiência, dos objetos enquanto se relacionam conosco, sujeitos, e não com a realidade em si, tal qual ela é, independentemente de qualquer relação com o conhecimento, pois o mundo dos fenômenos só existe na medida em que participamos dele. A obra de Arte para Kant é desinteressada, universalmente reconhecida por um sentimento ao mesmo tempo individual e coletivo. Contudo, as exigências kantianas ficam difíceis de serem cumpridas no século XXI, pois, neste momento, já não se pode mais conceber os juízos estéticos como puros e desinteressados; eles são, na maior parte das vezes, ditados por interesses mercadológicos.
} 
natureza humana arruinada, introduz questões que constituíram a base da estética marxiana. Ele nasceu em 1818 e foi um estudioso que exerceu grande influência sobre o pensamento filosófico, social e histórico da humanidade. Para Marx, o objetivo da vida é a felicidade ou o bem-estar. A sua obra é uma investigação extensiva sobre as condições materiais necessárias para realizar esse objetivo.

Nos Manuscritos econômico-filosóficos de 1844, esboçou uma concepção humanista de um comunismo que tinha como objetivo final a existência humana. Nessa ocasião, Marx, influenciado pela filosofia de Feuerbach, baseava-se no contraste entre a natureza alienada do trabalho no capitalismo e uma nova sociedade comunista na qual os seres humanos desenvolveriam livremente sua natureza em produção cooperativa. Com os Manuscritos, Marx tenta decifrar a sociedade civil de ordem burguesa. Ele cria uma teoria da ordem burguesa. Os Manuscritos não foram redigidos para publicação, mas criados como material de estudo. Eles são um texto de transição em que Marx desenvolve um conjunto de determinações que serão recorrentes em sua obra, um texto radical, entendendo que ser radical implica “agarrar a coisa pela raiz" (MARX, 2010, p.151).

Para Marx, a raiz do homem seria o próprio homem, pois o homem é uma constante tensão entre a sua genericidade humana, entre o seu ser genérico e a sua singularidade. O que é próprio do ser humano é existir como ser singular. Essa singularidade imediata que nos constitui é insuprimível; ela se transcende e se resolve na genericidade humana.

Ele considera que o homem é constituído de toda a sua referencialidade cultural, pois é o horizonte da cultura que o transcende e do qual ele é portador. O homem só se expressa singular e genericamente na medida em que é um ser objetivo. É aquele que só se mantém enquanto tal na medida em que se objetiva. A objetivação é a condição da existência humana. Ela se dá por meio de formas pouco perenes como o gesto, o riso, o movimento, a fala cotidiana, mas também por meio de formas mais privilegiadas, como a Ciência, a Arte, a Literatura etc. Esse conjunto de objetivações, que é o acervo da humanidade, deve ser apropriado pelos indivíduos, precisa ser subjetivado pelos indivíduos. Porém, o objeto produzido só se torna uma objetivação da humanidade quando o homem não se perde mais nele, ou seja, o objeto só existe para o sujeito na medida em que o sujeito desenvolveu a faculdade necessária à apreensão do objeto.

O homem rico, para Marx, não é aquele que tem; é aquele que é, pois o domínio da humanidade é o domínio do ser e não o domínio do ter. Para Marx, só é possível ser rico 
interiormente se se puder interiorizar a riqueza de objetivações da humanidade. Assim, a verdadeira riqueza é a elaboração das possibilidades criativas humanas, sem qualquer pressuposto além do desenvolvimento histórico anterior. Só o acesso às objetivações permite a subjetivação. Marx pensa no indivíduo socialmente constituído e, portanto, socialmente rico. Ninguém nasce rico ou pobre; é a sociedade que nos torna ricos ou não. É o sistema de objetivações que faz emergir e desenvolver o ser social. A humanidade se desenvolve na medida em que desenvolve seus sistemas de objetivações. ${ }^{3}$ Sobre isso, Marx e Engels pontuam:

\begin{abstract}
Vê-se como, em vez da riqueza e da miséria da economia política existe o homem rico e a necessidade humana rica. O homem rico é ao mesmo tempo aquele que tem necessidade de uma totalidade de manifestações humanas da vida. O homem para quem a sua própria realização existe como uma necessidade interior, como uma carência (MARX; ENGELS, 1986, p. 26).
\end{abstract}

Para Marx, a objetivação elementar que constitui o ser social é o trabalho. Ao conjunto dessas objetivações estaria reservado o conceito de práxis. Ele considera que o ser humano é prático e social. Esse caráter do homem é exemplificado paradigmaticamente pelo trabalho, objetivação privilegiada que garante a condição humana. O trabalho é a condição eterna do homem, integra a sua essência, ou seja, é o conjunto de atributos, qualidades que o ser humano, ao longo da sua trajetória na terra, conseguiu realizar.

A partir das ideias de Marx, consideramos o trabalho como uma atividade ontológica, estruturante do ser social que proporciona a participação legítima nos benefícios da riqueza social. Esses benefícios se distinguem das formas históricas e alienantes de exploração do trabalhador, presentes na produção capitalista. A concepção ontocriativa de trabalho não se reduz à atividade laborativa ou ao emprego, mas refere-se à produção de todas as dimensões da vida humana. Por meio dos estudos de Marx (2001), compreendemos o trabalho como práxis que possibilita criar e recriar, não apenas no plano econômico, mas no âmbito da arte e da cultura.

Contudo, com a crescente instrumentalização da natureza e da humanidade, o processo do trabalho afasta cada vez mais os indivíduos das vivências sensíveis. "Esta mutilação do homem, ou perda do humano, se dá precisamente no trabalho, na produção material, isto é, na

\footnotetext{
${ }^{3}$ Contudo, nem sempre as potencialidades criativas humanas são eficazes em termos de bem-estar. Isso se deve ao fato de que algumas capacidades humanas podem ser destrutivas, como, por exemplo, a construção de campos de concentração (EAGLETON, 1993).
} 
esfera na qual o homem deveria se afirmar como tal e que tornou possível a própria criação estética” (VÁZQUEZ, 1968, p. 52). Nesse sentido, a estética é uma esfera essencial para a busca do humano perdido. Ela pode esclarecer quanto o homem perdeu com a sociedade capitalista e vislumbrar uma nova sociedade na qual dominem relações verdadeiramente humanas.

Diante desses pressupostos, defendemos a ideia de que a Educação Estética é fundamental no processo educativo. E, nesse contexto, a arte precisa ser compreendida como mediação na formação omnilateral dos sujeitos. Uma formação voltada para o desenvolvimento total, completo e pleno. A arte surgiu por intermédio do trabalho, quando a fabricação dos instrumentos se sofisticou e possibilitou a elevação do domínio do homem sobre a matéria. Foi quando os objetos passaram a ter valor para além da utilização, mas pela materialização da alta possibilidade criadora do homem (VÁZQUEZ, 1968). Assim, partimos do pressuposto de que a obra de arte é um objeto no qual o sujeito se expressa, se exterioriza e se reconhece.

Ela possui a função de humanizar o próprio homem, pois é no curso das relações sociais que os indivíduos produzem, se apropriam e transformam as diferentes atividades práticas e simbólicas em circulação na sociedade em que vivem, e as internalizam como modos de ação/elaboração próprios, constituindo-se como sujeitos. Desse modo, como dissemos, para o indivíduo se constituir como ser humano, é preciso que internalize as produções humanas que foram sistematizadas na trajetória da humanidade (a arte é um exemplo dessas produções). Nesse contexto, para se conhecer um objeto, como a obra de arte, é preciso revelar sua estrutura social, apresentar o mundo das mediações, dos processos sociais (econômicos, políticos, científicos, culturais etc.) em que o objeto está inserido. Nesse sentido, a arte constitui-se como mediação entre o homem e o mundo. Portanto, é elemento mediador que permite a explicitação e o reconhecimento coletivo da relação dialética estabelecida entre o homem e a realidade.

\footnotetext{
A Arte (e com ela as imagens) é produto do homem inserido em um contexto social dinâmico e plural. Produzidas pelo trabalho humano, as imagens estão referidas ao modo de produção e às relações de classe e interesses sociais dos homens que as criaram. Dessa forma, o desafio de analisá-las pressupõe o desvelamento de sua materialidade histórico-social, ou seja, sua reconstituição histórica (FOERSTE, 2012, p. 173).
}

No entanto, o homem, muitas vezes, é manipulado pela sociedade capitalista pela via 
da arte. Um dos modos de manipulação se dá por meio da arte de massas ou pseudoarte. É uma arte que, deixando o homem na superfície ou na margem das coisas, se distingue por utilizar uma linguagem astutamente fácil, que corresponde à sua falta de profundidade humana (VÁZQUEZ, 1968). Nesse sentido, na sociedade capitalista contemporânea, pode-se dizer que a verdadeira obra de arte tem uma função muito importante, tendo em vista que o mundo é regido pelo consumo e pela alienação do homem. A arte, por ser expressão e objetivação do homem, “[...] é um dos caminhos mais valiosos para reconquistar, testemunhar e prolongar a verdadeira riqueza humana" (VÁZQUEZ, 1968, p. 127). Assim, a função social da arte é tornar possível uma vivência estética cada vez mais profunda e humana, pois ela é um dos meios mais fecundos que o homem possui para elevar-se enquanto tal. Toda obra de arte, por ser produto do trabalho do homem, estabelece, por essência, um diálogo com as particularidades de época, classe, nação, com os homens de ontem, hoje e amanhã. Portanto, para compreender a gênese da produção da obra de Arte é necessário considerá-la como produto da história e do cotidiano, imersa nos conflitos sociais e tocada por eles.

Acreditamos, desse modo, que a arte pode contribuir para a educação dos sentidos humanos. Porém, o ensino da arte não pode ser considerado o único responsável pela Educação Estética, pois essa deve permear todos os conhecimentos abordados na escola no que chamamos de uma educação integral/omnilateral. Além disso, consideramos que imagens artísticas podem ser mediadoras de um conhecimento sensível, um conhecimento pouco explorado na escola tradicional.

Diante desses pressupostos e reflexões, na próxima seção, apresentaremos as ideias de Vigotski sobre Educação Estética.

\section{CONTRIBUIÇÃO DE VIGOTSKI PARA OS ESTUDOS SOBRE EDUCAÇÃO ESTÉTICA}

A história da educação moderna é marcada pela presença da racionalidade instrumentalizadora, pragmática e burguesa e, também, pela ausência da racionalidade sensível.

O pleno sentimento da vida implica em que tentemos capturá-la e, assim, compreendê-la, de todas as maneiras possíveis - lógicas e estéticas, intelectuais e estésicas, científicas e artísticas. Não há porque privilegiar-se uma única e exclusiva maneira de contato com a realidade, feito intentado pela lógica da modernidade ao longo desses últimos séculos. (DUARTE JÚNIOR, 2000, p. 192). 
Nesse sentido, é necessário ampliar os modos academicamente aceitos de se conhecer a vida. Isso consiste numa discussão mais ampla da vida e do mundo. De modo contrário, uma educação centrada sobre as faculdades humanas isoladas,

[...] como intelecto ou a sensibilidade, só pode mesmo resultar em indivíduos dotados de um profundo e básico desequilíbrio: ao sensível e ao inteligível devem ser propiciadas condições equânimes de desenvolvimento, sob a pena da produção de seres humanos arraigadamente desequilibrados, como the soe acontecer nos dias em que vivemos (DUARTE JÚNIOR, 2000, p. 174-175).

Tal separação entre as faculdades humanas deveria ser algo impossível de acontecer, porque essas dimensões humanas são, em tese, inseparáveis.

Diante dessas questões, cabe indagar como seria possível pensar a Educação Estética, uma Educação do Sensível, no contexto da escola. É possível pensar que, apesar da consolidação de várias leis que regulamentaram a educação brasileira, a formação humana integral não se consolidou. Cada vez mais, fica evidenciada a busca por uma educação voltada para a técnica, distanciada do conhecimento sensível. Estudos realizados pelos pesquisadores da área (CIAVATTA, 2005; DUARTE JÚNIOR, 2000) mostram quão longe estamos da formação humana integral.

É preciso propor modos de negar/desconstruir/resistir os/aos sistemas opressores que integram a sociedade capitalista e que abafam a sensibilidade humana. Por isso, a importância da Educação Estética como modo de contribuir com o desvelamento dos sistemas opressores, fragmentadores e insensíveis. Vislumbramos possibilidades de discutir sobre essa problemática a partir das ideias de Vigotski (2010), pois ele problematiza de modo muito interessante a Educação Estética na escola de seu tempo.

Antes de apresentar tal discussão, cabe apontar que Vigotski ${ }^{4}$ parte das ideias de Marx para compor uma nova psicologia do desenvolvimento humano. Considera que organismo e meio exercem influência recíproca, portanto, o biológico e o social estão sempre associados aos processos de desenvolvimento dos sujeitos. Parte da premissa de que o homem se constitui como tal por meio das interações sociais. Percebe-o como alguém que transforma e é

\footnotetext{
${ }^{4}$ Cabe colocar que os livros de Vigotski chegaram ao Brasil recentemente, na década de 80, traduzidos de versões americanas que censuraram muitas das suas ideias ligadas ao marxismo. Algumas reflexões sobre os problemas de tradução na obra de Vigotski e suas repercussões no campo da Educação foram sistematizadas por Zoia Prestes (2010).
} 
transformado nas relações produzidas em uma determinada cultura. Nesse sentido, é na interação dialética do homem com seu meio que se originam suas funções psicológicas superiores. ${ }^{5}$ Essa relação do homem com o mundo não é uma relação direta, mas sim mediada por meios que se constituem nas ferramentas auxiliares da atividade humana. É por intermédio desses instrumentos e signos que os processos de funcionamento psicológico são fornecidos pela cultura.

Dessa forma, só ocorre o processo de desenvolvimento das funções psicológicas superiores quando o aprendizado se efetiva. Esse aprendizado se dá a partir da interação dos indivíduos e, também, no âmbito da educação escolar. Para Vigotski (1987), a escola ${ }^{6}$ oferece conteúdos, desenvolve modalidades de pensamento bastante específicas e tem papel insubstituível na apropriação das vivências ${ }^{7}$ culturalmente acumuladas. A escola é um elemento imprescindível para a realização plena do desenvolvimento dos indivíduos, já que promove um modo mais sofisticado de analisar e generalizar os elementos da realidade. Nela ocorrem, pelo menos em tese, atividades educativas ${ }^{8}$ sistematizadas intencionadas em tornar acessível o conhecimento formalmente organizado.

Para o psicólogo russo, um dos modos de os sujeitos se apropriarem da vivência culturalmente acumulada acontece por intermédio da Educação Estética. Contudo, muitas vezes as concepções acerca do papel da estética na vida do sujeito são vistas na escola de modo antagônico. Quase sempre essas concepções não tratam a Educação Estética como um objetivo em si, mas apenas como um meio para atingir resultados pedagógicos estranhos à estética. "Essa estética a serviço da pedagogia sempre cumpre funções alheias e, segundo os

\footnotetext{
${ }^{5}$ As funções psicológicas superiores consistem no modo de funcionamento psicológico tipicamente humano, como a capacidade de planejamento, memória voluntária e imaginação. Esses processos mentais são considerados superiores, porque se referem a mecanismos intencionais, ações conscientemente controladas, processos voluntários que dão ao indivíduo a possibilidade de independência em relação às características do momento e do espaço presente. Vigotski (1987) e seus colaboradores buscaram a comprovação dessas ideias por meio de experimentos com crianças e de investigações das formas de organização dos processos mentais em indivíduos de diferentes culturas. Esse estudo permitiu a definição de diversas linhas de pesquisa.

${ }^{6}$ É preciso lembrar que a presença na escola não é garantia de que o indivíduo se aproprie dos conhecimentos. $\mathrm{O}$ acesso ao saber dependerá de fatores sociais, políticos, econômicos, tendo em vista que a escola não é uma instituição independente, ela está inserida em uma trama social.

${ }^{7}$ Para Prestes (2010), algumas traduções dos textos de Vigotski substituíram a palavra vivência pela palavra experiência. Contudo, a palavra experiência não corresponde ao significado que é atribuído pelo psicólogo russo ao conceito de vivência que se relaciona com viver uma determinada situação, deixando-se afetar profundamente por ela.

${ }^{8} \mathrm{Na}$ sociedade contemporânea, a exclusão, o fracasso e a evasão escolar impedem a apropriação do saber sistematizado, da construção de funções psicológicas mais sofisticadas, de instrumentos de atuação e transformação de seu meio social e de condições para a construção de novos conhecimentos (REGO, 1995).
} 
pedagogos, deve servir de via e recurso para educar o conhecimento, o sentimento ou a moral" (VIGOTSKI, 2010, p. 324).

Vigotski critica a finalidade moral da arte, mais especificamente da Literatura, dizendo que

Organizam-se bibliotecas infantis com a finalidade de que as crianças tirem dos livros exemplos morais ilustrativos e lições edificantes, a enfadonha moral da rotina e os sermões falsamente edificantes se tornaram uma espécie de estilo obrigatório de uma falsa literatura infantil. (VIGOTSKI, 2010, p. 324).

O autor ressalta, ainda, que o adulto, supondo que o sentimento sério é inacessível à criança e, por conseguinte, ao jovem, adocica sem habilidade, nem arte, as situações e os heróis: substitui o sentimento pela sensibilidade e a emoção pelo sentimento. "O sentimentalismo não é outra coisa senão uma tolice do sentimento" (VIGOTSKI, 2010, p. $325)$.

Apesar da expectativa em obter resultados que atinjam o efeito moral esperado, muitas vezes isso não acontece. Como exemplo Vigotski cita a relação da Fábula da Cigarra e a Formiga e a escola.

[...] na fábula 'A Cigarra e a Formiga' a simpatia das crianças foi provocada pela cigarra despreocupada e poética, que passou o verão inteiro cantando enquanto a Formiga sombria e enfadonha lhes pareceu repugnante, assim como a fábula lhes pareceu direcionada contra a avareza estúpida e presunçosa da Formiga. Mais uma vez o bardo da zombaria foi orientado para o lado errado, e em vez de infundir nas crianças o respeito à diligência e ao trabalho a fábula suscitou nelas a sensação de alegria e beleza da vida leve e despreocupada. (VIGOTSKI, 2010, p. 326-327).

Assim, para Vigotski, a escola procura, muitas vezes, enquadrar qualquer vivência estética em um conhecimento do dogma moral sem assimilar esse dogma, sem suspeitar que o texto artístico frequentemente não ajuda a apreendê-lo, ao contrário, infunde uma concepção moral de ordem justamente oposta. Sob essa concepção, a obra de arte perde qualquer valor autônomo, torna-se uma espécie de ilustração para uma tese moral de cunho geral; toda a atenção se concentra precisamente nessa última, ficando a obra fora do campo de visão do educando.

[...] sob essa interpretação não só não se constroem nem se educam hábitos e habilidades estéticas, não só não se comunicam flexibilidade, sutileza e diversidade de formas às vivências estéticas como, ao contrário, transforma-se em regra pedagógica a transferência da atenção do aluno da própria obra para o seu sentido moral. O resultado é um amortecimento sistemático do sentimento estético, sua 
substituição por um momento moral estranho à estética e daí a natural repugnância estética. (VIGOTSKI, 2010, p. 328).

Um outro equívoco, apontado por Vigotski, é pensar que a arte é uma espécie de cópia da realidade. Houve um momento no qual os críticos concebiam que a obra de arte reunia e comportava em si os traços típicos da intelectualidade que podiam servir como material fidedigno para o estudo de qualquer época. Entretanto, Vigotski afirma que é fácil mostrar que a verdade da realidade da obra de arte se dá a partir de relações sumamente complexas: “[...] a realidade sempre aparece na arte tão transfigurada e modificada que não há como transferir diretamente o sentido dos fenômenos da arte para os fenômenos da vida" (VIGOTSKI, 2010, p. 330). Para ele, ao aderirmos à concepção de que a arte é reflexo direto da realidade, arriscamo-nos “[...] não só a ficar com uma concepção falsa da realidade como também a excluir inteiramente os momentos puramente estéticos no ensino" (VIGOTSKI, 2010, p. 330). Isso se explica pelo fato de que muitas vezes o artista possui outras reações ao seu contexto e se vale apenas de um material comum para atender a diferentes necessidades.

Mais um erro cometido pela pedagogia tradicional ocorre quando se reduz a estética ao sentimento do agradável, ao prazer pela obra de arte, com um objetivo em si. Isso “[...] reduz todo o sentido das emoções estéticas ao sentimento imediato de prazer e alegria que elas suscitam na criança" (VIGOTSKI, 2010, p. 331). Para Vigotski, nessa concepção, a arte é vista como um meio de despertar reações hedonísticas (fonte de prazer).

Nesse sentido, Vigotski critica a pedagogia tradicional por ter caído em um impasse nas questões da Educação Estética, justamente ao tentar impor objetivos estranhos e não inerentes a essa educação. Então, em que isso resultou? A pedagogia tradicional deixou escapar o próprio significado da Educação Estética e obteve resultados contrários aos esperados.

Sobre as concepções relativas à estética, Vigotski pontua que, durante muito tempo, manteve-se o ponto de vista de que a percepção estética é uma vivência passiva, entregue à impressão, é a cessação de qualquer atividade do organismo. Os psicólogos acreditavam que a condição indispensável para a possibilidade de realização da reação estética partia do desinteresse, da contemplação desinteressada, da ausência de qualquer posição pessoal em face do objeto estético. Essa concepção liga-se às ideias de Kant (1995a, 1995b, 1995c) sobre a contemplação desinteressada. Para Kant, o homem, em sua busca pelo conhecimento de mundo, precisa procurar também a harmonia com o mundo, pois, para haver conhecimento, é 
preciso que as nossas faculdades se ajustem à realidade material. É a contemplação dessa forma pura de cognição, a harmonia com o mundo, que vem a ser estética. O filósofo acredita que existem duas fontes do conhecimento humano: a sensibilidade e o entendimento. Por meio da primeira, os objetos nos são dados; pela segunda, são pensados. Só pela conjugação desses dois elementos é possível a experiência do real. Portanto, para Kant, não somos capazes de conhecer as coisas como elas são em si, só conhecemos realmente o mundo dos fenômenos, da experiência, dos objetos enquanto se relacionam conosco, sujeitos, e não com a realidade em si, tal qual ela é, independentemente de qualquer relação com o conhecimento, pois o mundo dos fenômenos só existe na medida em que participamos dele. A obra de Arte para $\mathrm{Kant}^{9}$ é desinteressada, universalmente reconhecida por um sentimento, ao mesmo tempo, individual e coletivo.

Vigotski critica essa tendência ao dizer que é essa uma noção que compreende uma meia-verdade, pois fornece uma ideia falsa da natureza da reação estética no seu conjunto. Para o autor, a obra de arte não é percebida quando o organismo está em completa passividade tampouco é percebida só pelos ouvidos e os olhos, mas também em atividade interior complexa, na qual o contemplar e o ouvir são apenas o primeiro momento, o primeiro impulso, o impulso básico.

\begin{abstract}
Se o destino de um quadro consistisse apenas em afagar o nosso olho e o da música em provocar emoções agradáveis ao nosso ouvido, a percepção dessas artes não apresentaria nenhuma dificuldade e todos, com exceção dos cegos e surdos, estariam igualmente chamados a perceber essas artes. Entretanto, os momentos de percepção sensorial das estimulações são apenas os impulsos primários necessários para despertar uma atividade mais complexa e em si carecem de qualquer sentido estético. 'Distrair os nossos sentimentos', diz Christiansen, 'não é o objetivo final da intenção artística'. O principal na música é o que não se ouve, nas artes plásticas o que não se vê nem se apalpa. (VIGOTSKI, 2010, p. 333).
\end{abstract}

Segundo o autor, a emoção estética pressupõe a existência de três momentos: estimulação, elaboração e resposta. O momento da percepção sensorial da forma, aquele trabalho desempenhado pelo olho e o ouvido, constitui apenas o momento primeiro e inicial da vivência estética. Para o autor, a arte é um "[...] sistema especialmente organizado de impressões externas ou interferências sensoriais sobre o organismo" (VIGOTSKI, 2010, p.

\footnotetext{
9 As exigências kantianas ficam difíceis de serem cumpridas no século XXI, pois, na contemporaneidade, a arte cada vez mais servirá aos interesses múltiplos, como a busca desenfreada pelo lucro, a espetacularização e a diversão.
} 
333). Entretanto, essas interferências sensoriais estão organizadas e construídas de tal modo que estimulam no organismo um tipo de reação diferente do que habitualmente ocorre, e essa atividade específica, vinculada aos estímulos estéticos, é o que constitui a natureza da vivência estética. Nessa vivência estética, o espectador constrói suas reações a partir das impressões externas (elementos que compõem a obra como suporte, formas, cores, textura etc.), criando o objeto estético.

Realmente, talvez o quadro não represente simplesmente um pedaço de pano quadrangular com certa quantidade de tinta aplicada sobre ele. Mas quando o espectador interpreta esse pano e essas tintas como a representação de um homem, um objeto ou ação, o complexo trabalho de transformação do pano pintado em quadro pertence inteiramente ao psiquismo do receptor. É necessário correlacionar de tal modo as linhas, fechá-las em tais contornos, relacioná-las entre si, interpretálas de tal modo em que perspectiva e transferi-las para o espaço a fim de que elas lembrem uma figura humana ou paisagem. (VIGOSTKI, 2010, p. 334).

Para perceber a obra de arte, faz-se necessário um complexo trabalho de memorização e associação de pensamento para se entender, por exemplo, que homem ou que paisagem estão representados no quadro, em que relação estão as suas diferentes partes. Todo esse trabalho necessário pode ser chamado de síntese criadora secundária, porque requer de quem percebe reunir em um todo e sintetizar os elementos dispersos da totalidade artística. Para o autor,

[...] se uma melodia diz alguma coisa a nossa alma é porque nós mesmos sabemos arranjar os sons que nos chegam de fora [...]. Todo o conteúdo e os sentimentos que relacionamos com o objeto da arte não estão contidos nela mas são por nós incorporados, como que projetados nas imagens da arte, e os psicólogos denominaram de empatia o próprio processo de percepção. (VIGOSTKI, 2010, p. 334, grifo nosso).

Vigotski comenta que essa atividade de empatia consiste num reatamento de uma série de reações internas, da sua coordenação vinculada, e em certa elaboração criadora do objeto que constitui o dinamismo estético básico que, por sua natureza, é um dinamismo do organismo que reage a um estímulo externo.

$\mathrm{Na}$ tentativa de entender o sentido biológico da atividade estética, o autor compreende, a partir da elucidação da psicologia da criação do artista e na aproximação entre a percepção e 
o processo de criação, que a criação ${ }^{10}$ é uma necessidade do nosso psiquismo. Parte do conceito da psicologia moderna de que a criação é sublimação, ou seja, transformação de modalidades inferiores de energia psíquica, que não foram utilizadas nem encontraram vazão na atividade normal do organismo, em modalidades superiores. Para ele,

[...] nas questões de criação temos diante de nós como que pessoas ricas e pobres, umas gastando toda a reserva de sua energia para manter a sua sobrevivência diária, outras como que guardando e economizando, ampliando o currículo de necessidades a serem atendidas. Também aqui a criação surge do instante como certa energia não acionada, não utilizada e uma destinação imediata, ela permanece irrealizada e se desloca para além do limiar da consciência, de onde retorna transformada em novas modalidades de atividade. (VIGOTSKI, 2010, p. 337).

Para Vigotski, realiza-se na vida do homem apenas uma parte de todas as excitações que surgem no sistema nervoso, e a criação cobre inteiramente o resíduo que fica entre as possibilidades e a realização, o potencial e o real na nossa vida. De acordo com autor, ser Shakespeare e ler Shakespeare são fenômenos diversos pelo grau, mas idênticos pela natureza: "O leitor poder ser congenial ao poeta e, ao percebermos uma obra de arte, nós sempre a recriamos de forma nova. É legítimo definir os processos de percepção como processos de repetição e recriação do ato criador" (VIGOTSKI, 2010, p. 338).

Por conseguinte, Vigotski considera que a arte surge em nossa vida como forma de excitação do sistema nervoso que permanece de modo irrealizado na atividade, porque o sistema nervoso recebe um volume de excitações superior ao que pode reagir. Porém, o excedente do comportamento não realizado deve encontrar alguma vazão. Se o sistema nervoso não encontra a devida vazão, surgem formas anormais de comportamento sob o aspecto de psicoses e neuroses que significam o conflito da aspiração do subconsciente não realizada com a parte consciente do nosso comportamento. Sobre isso o autor coloca que

Para o que não se realiza na vida existem apenas duas saídas: a sublimação ou a neurose. Assim, do ponto de vista psicológico a arte constitui um mecanismo biológico permanente e necessário de superação de excitações não realizadas na vida e é um acompanhante absolutamente inevitável da existência humana nessa ou naquela forma. (VIGOTSKI, 2010, p. 338, grifo nosso).

\footnotetext{
${ }^{10}$ Segundo Prestes (2010), Vigotski refere-se à criação como um processo e não como uma qualidade ou característica de quem é criativo (criatividade).
} 
Assim, “[...] na criação artística a sublimação se realiza em formas tempestuosas e grandiosas, realizando-se na percepção artística nas formas dos estilos que a nós se dirigem, formas essas atenuadas, simplificadas e antecipadamente preparadas pelo sistema" (VIGOTSKI, 2010, p. 338, grifo nosso). Portanto, a Educação Estética tem um importante papel na criação de habilidades permanentes para a sublimação do subconsciente.

Educar esteticamente alguém significa criar nessa pessoa um conduto permanente e de funcionamento constante, que canaliza e desvia para necessidades úteis a pressão interior do subconsciente. A sublimação faz em formas socialmente úteis o que o sonho e a doença fazem em formas individuais e patológicas. (VIGOTSKI, 2010, p. 338).

O que o autor russo diz é de suma importância para a Educação Estética. Indica que é fundamental promover momentos de criação artística, pois assim o indivíduo canalizará e desviará suas pressões interiores por via da arte.

Vigotski nos ajuda a perceber que o objetivo final da reação estética não é repetir alguma reação real, mas superá-la e vencê-la. Portanto, uma obra de arte vivenciada pode ampliar a nossa concepção de algum campo de fenômenos, levar-nos a ver esse campo com novos olhos, a generalizar e unificar fatos dispersos. Como qualquer vivência intensa, a vivência estética cria uma atitude muito sensível para o nosso comportamento, como se, a partir dessas vivências, pudéssemos acumular energia para futuras ações, dando a essas ações um sentido e um mundo novos.

O prazer provocado por obras de arte sempre surge por via indireta e contraditória e decorre forçosamente da superação de impressões imediatas causadas pelo objeto e pela arte. Para Vigotski,

É necessário ver o feio em toda a sua força para depois colocar-se acima dele no riso. É necessário vivenciar com o herói da tragédia todo o desespero da morte para com o coro elevar-se sobre ela. A arte implica essa emoção dialética que reconstrói o comportamento e por isso ela sempre significa uma atividade sumamente complexa de luta interna que se conclui na catarse ${ }^{11}$. (VIGOTSKI, 2010, p. 345).

De acordo com o autor russo, a relação da vivência estética com a educação se dilui em três questões:

\footnotetext{
${ }^{11}$ Para Vigotski, a catarse relaciona-se com a "[...] liberação das paixões despertadas pela tragédia que constitui um objetivo final da Arte. O horror não é representado em prol de si mesmo, mas como impulso para a sua superação" (VIGOTSKI, 2010, p. 345).
} 
a) Educar a criação - o desenho ensina o sujeito a dominar o sistema das suas experiências e a vencê-las e superá-las. Ensina a ascensão ao psiquismo. Por exemplo: a criança que desenha um cão vence, supera e coloca-se acima de experiência imediata. A correção do desenho significa uma grosseira interferência na estrutura psicológica da vivência da criança e ameaça servir como obstáculo a tal vivência. Por isso, o autor defende a plena liberdade da criação infantil, a renúncia à tendência a equipará-la com a consciência do adulto e o reconhecimento da sua originalidade. Existe a tendência da criança à liberdade e à independência em relação ao desenho real dos objetos. Isso não significa que a criança não consegue ver os objetos como eles são, mas que ela deforma os aspectos secundários do objeto em proveito dos aspectos mais importantes dele.

b) Ensinar as habilidades técnicas da arte - para Vigotski, é impossível penetrar na obra de arte alheio à técnica de sua linguagem. Por isso, defende que seja oportunizado, na educação, o mínimo conhecimento técnico da estrutura de qualquer obra. "Neste sentido agem de forma integralmente pedagógica aquelas escolas nas quais o domínio da técnica de cada arte se torna condição indispensável da formação" (VIGOTSKI, 2010, p. 350). Complementa ao falar que o ensino da técnica deve ser combinado com a própria criação do sujeito e da cultura das suas percepções artísticas. Assim, só será útil aquele ensino da técnica que vai além da técnica e que ministra um aprendizado criador, ou de criar, ou de perceber.

c) Educar o juízo estético, ou seja, as habilidades para perceber e vivenciar obras de arte - o autor critica alguns pedagogos que pensavam que observar, ouvir e sentir prazer fosse tão simples que não necessitava de nenhuma aprendizagem especial. Contrário a essa opinião, Vigotski considera que esse é o objetivo principal e o fim da educação geral.

O sistema geral da educação social visa a ampliar ao máximo os âmbitos da experiência pessoal e limitada, estabelecer contato entre o psiquismo da criança e as esferas mais amplas da experiência social já acumulada, como que incluir a criança na rede mais ampla possível da vida. Essas finalidades gerais determinam inteiramente também os caminhos da Educação Estética. A humanidade acumulou na arte uma experiência tão grandiosa e excepcional que qualquer experiência de criação doméstica e de conquistas pessoais parece ínfima e mísera em comparação com ela. Por isso, quando se fala de Educação Estética no sistema de educação geral sempre deve-se ter em vista essa incorporação da criança à experiência Estética da sociedade humana: incorporá-la inteiramente à arte monumental e através dela incluir o psiquismo da criança naquele trabalho geral e universal que a sociedade 
humana desenvolveu ao longo dos milênios, sublimando na arte o seu psiquismo. (VIGOTSKI, 2010, p. 351-352).

Assim, a interpretação da obra de arte é o procedimento que exige um aprendizado especial, “[...] a elaboração de habilidades específicas de recriação das obras de arte e, neste sentido, as aulas de observação de quadros e leitura lenta, introduzidas em algumas escolas europeias, são um modelo de Educação Estética” (VIGOSTSKI, 2010, p. 352, grifo nosso).

Ainda sobre a educação do juízo estético, considera que é preciso introduzir a Educação Estética na própria vida, pois a arte transfigura a realidade das construções da fantasia e, também, da elaboração real dos objetos e situações. A casa e o vestuário, a conversa e a leitura e a maneira de andar, tudo isso pode servir como material para a elaboração estética.

\begin{abstract}
De coisa rara e fútil a beleza deve transformar-se em uma exigência do cotidiano. $\mathrm{O}$ esforço artístico deve impregnar cada movimento, cada palavra, cada sorriso da criança. É de Potiebniá a bela afirmação de que, assim como a eletricidade não existe só onde existe a tempestade, a poesia também não existe só onde há grandes criações da arte, mas em toda parte onde soa a palavra do homem. E é essa poesia de "cada instante" que constitui quase que a tarefa mais importante da educação estética. (VIGOTSKI, 2010, p. 352).
\end{abstract}

Sobre a Educação Estética e o talento, Vigotski afirma que não se deve perguntar por que uma pessoa tem mais ou menos talento, uma vez que um alto grau de talento original do ser humano é um fato básico em todos os campos do psiquismo e, consequentemente, são passíveis os casos de explicação, os casos de diminuição e perda de talento. Portanto, a tarefa da Educação Estética

[...] deve partir da existência de um alto talento da natureza humana e da hipótese da existência de grandiosas potencialidades criadoras do ser humano e, assim, dispor e orientar as suas interferências educativas de modo a desenvolver e preservar tais potencialidades. O talento se torna também uma tarefa da educação. (VIGOTSKI, 2010, p. 363).

Nesse sentido, encontrar talentos, evidenciar talentos, não é função da educação, pois todos os indivíduos possuem as mesmas potencialidades criadoras. Marx já apontava para esse caminho.

Para Vigotski, a possibilidade criadora, para que cada um de nós se torne um coparticipante de Shakespeare em sua tragédia e em Beethoven em suas sinfonias, é o indicador mais nítido de que, em cada um de nós, existem um Shakespeare e um Beethoven. 
Vigotski vai às máximas alturas da potencialidade da criatividade humana. A partir das ideias marxianas, ele declara o potencial criador existente em todos seres humanos e apresenta de que modo isso pode ser valorizado pela escola do seu tempo.

Com base nas contribuições de Vigotski para a Educação Estética, o que podemos pensar sobre as práticas que temos na escola? Como pode a Educação Estética contribuir com a formação dos alunos tendo em vista todo o processo de racionalização instrumental que a escola sofre a partir da ciência moderna e da sociedade capitalista?

Para pensar sobre essas questões, faremos o resgate de algumas ideias aqui apresentadas na perspectiva de tê-las como pressupostos indispensáveis para essa discussão.

a) É preciso ajudar o indivíduo a desenvolver a criticidade, conduzindo-o à capacidade de refletir sobre as ideologias dominantes, postas principalmente pela mídia que compõe a grande Indústria Cultural ou, nos modos de dizer de Vázquez, a arte de massa. Faz-se necessário, então, refletir, negar, problematizar os meios de comunicação, os produtos da mídia e outros meios de alienação para contribuir com uma educação emancipadora.

b) É preciso ajudar o educando a se apropriar das objetivações humanas, pois, como Marx apontou, isso só ocorre de homem para homem, ou seja, pela interação.

c) É preciso ampliar ao máximo a vivência do aluno a partir do que a humanidade acumulou de grandioso na arte. Para uma Educação Estética, deve-se incorporar a vivência do sujeito à estética da sociedade humana.

d) O alto talento da natureza humana é comum a todos os homens, cabe à educação desenvolver tais potencialidades.

e) Para uma Educação Estética, é preciso: educar para a criação e reconhecer a originalidade da criação; ensinar habilidades artísticas combinadas com a própria criação do sujeito e da cultura das suas percepções artísticas; educar o juízo estético e ensinar a observar e ler lentamente as obras de arte.

Diante desses pressupostos, na seção que segue, apresentaremos uma proposta de Educação Estética por meio das Artes Visuais, tendo como foco específico a ideia de se propor leituras lentas das obras de arte. 


\section{UMA PROPOSTA DE EDUCAÇÃO ESTÉTICA POR MEIO DAS ARTES VISUAIS: A LEITURA LENTA DA OBRA DE ARTE}

Todos os aspectos apresentados desde as ideias de Vigotski sobre a Educação Estética são fundamentais. Contudo, no artigo em tela elencaremos um desses aspectos e faremos uma ampliação/um aprofundamento relacionado ao que o autor intitulou de leitura lenta da obra de arte.

Entendemos, a partir de Vigotski (2010) e das nossas vivências no campo do ensino da arte, que, para ocorrer uma leitura lenta, é preciso que se tenha um tempo para ver a obra de arte. Porém, não adianta colocar a imagem na frente do aluno e deixá-lo perceber isso sozinho. Isso seria reiterar a crença de que a percepção estética é uma experiência passiva, como alerta Vigotski (2010). Assim, é preciso ajudar o educando a analisar criticamente a obra de arte para perceber múltiplas relações intrínsecas a elas, que passam pelos aspectos contextuais, formais ${ }^{12}$ e por outros diálogos estabelecidos entre a imagem lida com outras obras de arte.

Desse modo, é necessário refletir sobre o contexto de produção da obra, o que não significa somente ir atrás de uma história pessoal de vida e de um trabalho artístico ou imaginar as reações de um leitor ansioso por completar lacunas de uma possível interpretação do texto lido. Entendemos que a imagem é o ponto de partida para que se possa compreender o contexto histórico no qual ela está inserida. É preciso interligar o contexto aos aspectos formais, sem dividir a leitura no que é contexto e o que é forma. Além disso, é importante colocar a obra analisada em diálogo com outras imagens do mesmo artista e/ou de outros. Por conseguinte, interligar a temática do artista com outros textos, como reportagens de revistas, músicas ou poesias para criar, a partir da leitura, uma rede de significações. Essa proposição reforça o fato de que todo texto se constrói como um mosaico de citações, todo texto é a absorção e transformação de um outro texto e, nessa ciranda de significações, o sujeito amplia o seu repertório cultural e sensível e se aproxima cada vez mais do universo do artista. ${ }^{13}$

Esta relação dialógica entre vozes no interior de uma obra de arte relaciona-se com o conceito de polifonia adotado por Bakthin (2000). Com base nessa ideia, é possível pensar

\footnotetext{
12 No caso da obra bidimensional seria, por exemplo, a linha, a cor, a textura, a forma, a composição e a técnica.

13 Trata-se do contexto de produção do artista, as suas referências para a criação, seus gostos, histórias etc.
} 
que o artista, assim como os leitores, está impregnado por diferentes textos visuais e/ou verbais vistos e lidos que vão compor os seus repertórios criativos. Desse modo, compreendemos que, para que a leitura de uma obra seja realizada de modo aprofundado, é preciso, além dos outros fatores citados, observar os indícios da presença de outras vozes e outros textos (os intertextos) na imagem analisada e, a partir dessas tramas, atribuir sentido a essas conexões. Como se, ao ler, pudéssemos traçar um possível caminho polifônico subjetivo e relativo a cada leitura de imagem realizada e também a cada leitor.

Indissociáveis à análise dos aspectos contextuais e intertextuais estão os aspectos formais, ou seja, a visualidade da imagem. A forma é uma mediação necessária para o conteúdo estético, “[...] pois este só surge a partir da relação totalmente estruturada, elaborada dos materiais" (FREITAS, 2003, p. 43).

É como se a forma da obra de arte, operando uma mediação entre nós e o mundo, acabasse nos fornecendo a possibilidade de vínculo imediato com ele, não obscurecido pela abstração conceitual, lógica. A experiência estética parece apontar para uma transcendência, uma ultrapassagem daquilo que nossos sentidos podem perceber e que nossa razão pode pensar. (FREITAS, 2003, p. 44).

No caso de uma pintura, desenho ou gravura, por exemplo, é necessário explorar as expressões das formas e de sua disposição no espaço, das cores, dos materiais empregados e dos contrastes plásticos como recursos capazes de construir significados. É preciso considerar as possibilidades de combinações de cores; se elas instalam ou não movimento e ritmo na composição criada pelo artista. Cabe identificar como foi realizado o emprego dessas cores: se são puras, complementares, análogas etc; a utilização ou não de tonalidades; os graus de saturação da cor; a variação ou a manutenção cromática e tonal; a luminosidade em seus graus variados e nos jogos entre claro/escuro.

Além de analisar as relações cromáticas estabelecidas, é necessário perceber como as combinações de linhas, volumes e cores superpostas proporcionam efeitos diferentes de simetria ou de perspectiva, por exemplo. Outros pontos a serem observados dizem respeito à materialidade e à técnica utilizada para criar a obra de arte. Quando se trata de uma pintura, podem-se observar as pinceladas, as marcas do gesto do artista, ou seja, a decisão do artista de deixar perceptível o ritmo impresso na obra que produziu, a espessura da pincelada, o modo como recobriu o suporte camada por camada ou a decisão de deixá-lo perceptível, o ritmo impresso pela maneira de fazer e, por fim, o relevo ou a textura que o gestual do artista cria na 
superfície pictórica. Nesse caso, a cor e a forma desencadeiam diferentes efeitos de sentido e são consideradas como marcas deixadas no ato de pintar. No campo ainda da pintura, podemse perceber as pinceladas: se são contidas, soltas, descendentes, ascendentes, diluídas, pastosas, lisas ou rugosas.

Outro ponto a ser observado é a posição e a orientação das formas que geram ou não movimento no suporte escolhido pelo artista, como elas se relacionam e que efeito essa organização composicional proporciona. Além disso, cabe observar o efeito proporcionado pelos diversos tipos de suporte que podem ser utilizados pelo artista, como madeira, tela, metal, papel etc. (REBOUÇAS, 2003).

Mais dois aspectos importantes de serem analisados, no caso da pintura, são o título da obra e a assinatura do artista. Segundo Oliveira (2004), quando um artista dá à sua obra um título verbal, ele a reelabora numa outra linguagem, a verbal. É como se o artista nos desse uma chave para entrar na obra de arte por ele produzida. Em contrapartida, existem artistas que não dão nomes às obras. "O não nomear ou a ausência dum nome num outro sistema já é por si mesmo uma espécie de título que guia o observador na tarefa de reconstruir a significação da obra" (OLIVEIRA, 2004, p. 130). Oliveira pontua que a assinatura do pintor é um dos modos de presença na tela. "Ele, que se presentifica no ato mesmo de organizar o seu discurso, aparece com essa outra marca, a da assinatura" (OLIVEIRA, 2004, p. 130). A assinatura é o selo do pintor que, ao terminar a obra, a identifica como sua e a envia do seu ateliê (mundo privado) para o mundo público. A assinatura é colocada quando não há nada mais a ser feito. Ela é o ponto final, ou a obra acabada.

Além disso, o modo como essa imagem foi distribuída e legitimada é fundamental e precisa ser analisado. Sobre esse assunto, Foerste (2012, p. 177) coloca que

[...] ler imagens constitui-se num desafio cotidiano de desvelamento de práticas e concepções humanas imbricadas na materialidade da imagem. Os modos particulares de produção, distribuição e recepção das imagens desafiam-nos a estudá-las como objeto que não se esgota em si mesmo, mas que está referido ao complexo campo de relações de que são produto, são preservadas, divulgadas e/ou recebidas. Percebe-se, então, que já não é possível ler imagens sob bases unicamente formalistas de análise, mas que essa análise implica encontro dos sujeitos. Trata-se do encontro do homem com o homem, mediados pelo objeto das intervenções humanas no mundo.

Nesse sentido, cabe perguntar: Onde a imagem analisada está localizada? Como se deu o acesso a essa imagem? Quem legitimou essa produção como obra de arte? Por que 
essa obra está no museu ou no livro, e não outra? Desse modo, seria incentivada uma postura crítica em relação aos Sistemas de Belas-Artes, ${ }^{14}$ para que os alunos se habituem a essa prática e se sintam capazes de fazer suas próprias escolhas culturais.

Assim, é possível pensar que estabelecer relações entre esses aspectos de modo indissociável pode colaborar com a leitura lenta proposta por Vigotski e ampliada por nós. Isso não significa que essa é uma fórmula que, se repetida, logrará êxito e proporcionará uma Educação Estética. É muito mais do que isso, envolve complexidade, reiterações e processualidades. Portanto, consideramos que a leitura lenta deve integrar - além de momentos de análises formais, conceituais, históricas e intertextuais - períodos de suspensão, um tempo entreimagens que possibilite uma reflexão profunda e vagarosa. Não em um momento pontual, mas em vários momentos que constituem um processo de convívios e de encontros com as obras de arte, um processo catártico. Esses momentos de encontro e de convívio com as imagens integram duas possibilidades de trabalho: a partir de reproduções das imagens (cópias de boa qualidade) ou com visitas aos espaços expositivos (ateliê do artista, museus, galerias de arte, centros culturais, entre outros).

Além disso, mais um fator que pode colaborar com a Educação Estética é a proposição de assuntos relacionados com os interesses dos alunos. Pensamos que a escola precisa se constituir como um espaço de debate, diálogo e autoria. Muitas vezes, os assuntos discutidos não são apreciados pelos alunos. Isso resulta, em alguns casos, numa desmotivação e num desinteresse em aprender. Não se trata de reiterar o conhecimento cotidiano do aluno, mas propor ampliações a partir de questões que emerjam da prática social do educando.

Não adianta disponibilizar o mais interessante objeto artístico a uma pessoa, se ela não tiver, além de estímulo e curiosidade, a capacidade de compreender de todos os modos, sentir

\footnotetext{
${ }^{14}$ Para Reis (2006, p. 3), a tarefa primordial do Sistema de Belas-Artes “[...] é identificar, classificar e qualificar um objeto quanto ao seu valor artístico segundo um conjunto de parâmetros e critérios teleológicos previamente definidos". O Sistema de Belas-Artes é o mantenedor e controlador do capital cultural da classe dominante. Para esse autor, a origem do Sistema de Belas-Artes surgiu e confunde-se com o processo de consolidação da burguesia brasileira, devido à necessidade de se estabelecer parâmetros úteis para os mecenas e compradores de objetos artísticos nos mercados existentes, para que assim fosse elaborado um código contendo noções gerais de Estética que serviam para "[...] balizar o valor artístico de uma obra, a produção geral de um artista e as suas qualidades enquanto tal" (REIS, 2006, p. 3). Frente às demandas dos séculos XVIII e XIX, foi preciso estabelecer um estatuto epistemológico para a arte, desenvolver uma visão crítica da arte, vê-la como um dos dispositivos produtivos e ideológicos sob o controle, muitas vezes, das classes dominantes. Isso nos coloca diante do senso de urgência quanto a operar o aparato conceitual e sensível da arte. Dessa forma, é preciso desenvolver na escola propostas que problematizem a história da arte brasileira e mostrem aos alunos as concepções ideológicas que estavam permeando as buscas por uma identidade artística brasileira.
} 
com outras capacidades humanas (inclusive o raciocínio) esse objeto. Caso isso não seja proposto, a pessoa será incapaz de se reconhecer no objeto artístico, ficará impossibilitada de estabelecer uma relação propriamente humana - sensível - com a obra de arte. Como diz Marx, os sentidos são historicamente constituídos. Eles se refinam e se humanizam a partir de um processo que é inerentemente social. No campo da educação, é possível pensar que esse processo pode acontecer na escola e precisa contar com diversificadas, intensas e sensíveis mediações.

\section{CONSIDERAÇÕES FINAIS}

Nas seções anteriores, apresentamos reflexões sobre a Estética e seu aspecto educativo, por meio das ideias de Marx e Vigotski. A partir de um dos pilares apontados por Vigotski quanto à Educação Estética, a leitura lenta, propusemos um aprofundamento que pode ser considerado como uma possibilidade de se educar esteticamente. Assim, consideramos que, ao proporcionar intensos, diversificados e contínuos encontros com obras de arte, mediar leituras de imagens que evidenciem tanto os aspectos poéticos e intertextuais quanto os formais dessas obras, ampliados pelo conhecimento do universo do artista e dos modos de legitimação e divulgação das obras e, por fim, propor assuntos relacionados com os interesses dos educandos, seria possível pensar em um modo de se contribuir com a Educação Estética do sujeito.

Consideramos que quanto mais intensas e sistematizadas forem as leituras de imagens maior será o nosso repertório cultural para sentirmos e significarmos o mundo e fazermos a leitura do que nos rodeia e nos acontece (LEITE, 1998, 2005). Como diz Vigotski (2009, 2010), a imaginação se alimenta e se realimenta de materiais tomados/apropriados da experiência vivida por nós. Quanto mais rica for a vivência humana, maior será o material disponível para a imaginação.

Diante dessas ideias é possível pensar em uma Educação Estética como um modo especial de formação dos sentimentos e dos gostos que possibilite o princípio criador em todas as atividades humanas e contribua com a formação de identidades, subjetividades e alteridades. Que busque ampliar, por meio da leitura lenta das imagens, o olhar do sujeito sobre o mundo, a natureza e a cultura, que diversifique e enriqueça suas vivências sensíveis - estéticas. Uma

Educação Estética que possa estimular outras necessidades e interesses, que promova outras 
buscas no sentido de transformação daquilo que é oferecido pelas mídias, por exemplo, por meio do estranhamento e da inversão do olhar que permita e que busque intensamente a ação criadora.

\title{
READING SLOW ART WORK AS A MOTION FOR AESTHETIC EDUCATION ON THE BASIS OF MARX AND VYGOTSKY CONTRIBUTIONS
}

\begin{abstract}
The article signals a proposal for Aesthetic Education, from literature search, in dialogue with studies of Marx and Vygotsky. According to the Marxist theory presents reflections on aesthetics in the contemporary context and seeks to understand Vygotsky assumptions of Aesthetic Education. Suggests a path through the visual arts, to educate aesthetically from the concept of slow reading of the artwork. Considers that one of the possibilities to achieve such intent is to provide intense, diverse and ongoing encounters with works of art; mediate readings pictures that show both poetic and intertextual aspects as formal of these works, magnified by the knowledge of the artist's universe and the legitimation modes and dissemination of works and, finally, to propose matters relating to the interests of students.
\end{abstract}

Keywords: Aesthetic Education; Art; Vygotsky; Marx

\section{LECTURA LENTA DE TRABAJO DE ARTE COMO PROPUESTA DE EDUCACIÓN ESTÉTICA EN LA BASE DE CONTRIBUCIONES DE MARX Y VYGOTSKY}

\section{RESUMEN}

El artículo señala una propuesta de Educación Estética, a través de la búsqueda bibliográfica, en diálogo con los estudios de Marx y Vygotsky. De acuerdo con la teoría marxista presenta reflexiones sobre la estética en el contexto contemporáneo y busca entender supuestos Vygotsky de Educación Estética. Sugiere un camino a través de las artes visuales, para educar estéticamente desde el concepto de lectura lenta de la obra. Considera que una de las 
posibilidades para lograr tal propósito es proporcionar encuentros intensos, diversos y en curso con las obras de arte; mediar lecturas imágenes que muestran tanto los aspectos poéticos e intertextuales como formal de estas obras, magnificadas por el conocimiento del universo del artista y los modos de legitimación y difusión de las obras y, por último, para proponer los asuntos relacionados con los intereses de los estudiantes.

Palabras clave: Educación Estética; Art; Vygotsky; Marx

\section{REFERÊNCIAS}

BAKTHIN, Mikhail. Estética da criação verbal. São Paulo: Martins Fontes, 2000.

CIAVATTA, Maria. A formação integrada: a escola e o trabalho como lugares de memória e de identidade. In: FRIGOTTO, G.; CIAVATTA, M.; RAMOS, M. (Orgs.). Ensino médio integrado: concepção e contradições. São Paulo: Cortez, 2005.

DUARTE JÚNIOR, João Francisco. $O$ sentido dos sentidos: a educação (do) sensível. 2000. 234 p. Tese (Doutorado em Educação) - UNICAMP, Campinas, 2000.

EAGLETON, Terry. A ideologia da estética. Rio de Janeiro: Jorge Zahar Editor, 1993.

FOERSTE, Gerda Margit Schütz. Contribuições de Lukács na pesquisa com imagens na educação: um breve estudo das categorias trabalho, particularidade e mediação. In: FICHTNER, Bernd et al. (Orgs.). Cultura, dialética e hegemonia: pesquisas em educação. Vitória: EDUFES, 2012.

FREITAS, Verlaine. Adorno e a arte contemporânea. São Paulo: Zahar, 2003.

JAPIASSU, H.; MARCONDES, D. Dicionário básico de filosofia. Rio de Janeiro: Jorge Zahar, 2008.

KANT, Immanuel. Crítica da faculdade do juízo. Rio de Janeiro: Forense Universitária, 1995a.

Crítica da razão prática. Lisboa: Edições 70, 1995 b.

Crítica da razão pura. Lisboa: Edições 70, 1995c.

LEITE, Maria Isabel. Desenho infantil: questões práticas e polêmicas. In: LEITE, M. I.; KRAMER, S. (Orgs.). Infância e produção cultural. São Paulo: Papirus, 1998.

Museus de arte: espaços de educação e cultura. In: LEITE, M. I.; OSTETTO, L. E. 
(Org.). Museu, educação e cultura: encontros de crianças e professores com a arte. São Paulo: Papirus, 2005.

MARX, K.; ENGELS, F.. Sobre literatura e arte. São Paulo: Global editora, 1986. Crítica da filosofia do direito de Hegel. São Paulo: Boitempo, 2010. . Manuscritos econômico-filosóficos. São Paulo: Editora Martin Claret Ltda, 2001.

OLIVEIRA, Ana Cláudia. As semioses pictóricas. In: OLIVEIRA, A. C. (Orgs.). Semiótica plástica. São Paulo: Harker Editores, 2004.

PRESTES, Zoia Ribeiro. Quando não é quase a mesma coisa: análise de traduções de Lev Semionovitch Vigotski no Brasil, repercussões no campo educacional. 2010. 295 p. Tese (Doutorado em Educação) - Faculdade de Educação da Universidade de Brasília, Brasília, 2010.

REIS, Ronaldo Rosas. A abelha, o arquiteto e a escola: das relações de produção artística e do ensino da Arte no pós-modernismo. In: REUNIÃO ANUAL DA ASSOCIAÇÃO NACIONAL DE PÓS-GRADUAÇÃO E PESQUISA EM EDUCAÇÃO, 29. 2006, Caxambu. Anais... Caxambu: ANPED. Diposnivel em: http://www.anped.org.br/reunioes/29ra/trabalhos/trabalho/GT09-2168--Int.pdf>. Acesso: 22 Jun. 2015.

REBOUÇAS, Moema. O discurso modernista da pintura. Lorena: Fatea, 2003.

REGO, Teresa Cristina. Vygotsky: uma perspectiva histórico-cultural da educação. Petrópolis: Vozes, 1995.

SANTAELLA, Lúcia. Estética de Platão a Peirce. São Paulo: Experimento, 1994.

SCHILLER, Friedrich. Educação estética do homem. São Paulo: Iluminuras, 2002.

VÁZQUEZ, Adolfo Sánchez. As ideias estéticas de Marx. Rio de Janeiro: Paz e Terra, 1968

VIGOTSKI, Lev Semenovich. História Del desarrollo de las funciones psíquicas superiores. Cuba: Editorial Científico Técnica, 1987.

. Criação e imaginação na infância. São Paulo: Ática, 2009.

Psicologia pedagógica. São Paulo: Martins Fontes, 2010.

Data de recebimento: 29/03/2015

Data de aceite: 12/05/2015 